\title{
Lubrication Mechanism of Halogen-Free Ionic Liquids
}

\author{
Shouhei Kawada ${ }^{1)^{*}}$, Seiya Watanabe ${ }^{1)}$, Ryo Tsuboi ${ }^{2)}$, Shinya Sasaki ${ }^{3)}$ and Braham Prakash ${ }^{4}$ \\ 1)Graduate School of Tokyo University of Science, 6-3-1 Niijuku, Katsushika-ku, Tokyo 125-8585, Japan \\ 2)Daido University, 10-3 Takiharucho, Minami-ku, Nagoya 457-8530, Japan \\ 3)Tokyo University of Science, 6-3-1 Niijuku, Katsushika-ku, Tokyo 125-8585, Japan \\ 4)Luleå University of Technology, SE 97187 Luleå, Sweden \\ *Corresponding author: Shouhei Kawada (4515702@ed.tus.ac.jp)
}

Manuscript received 13 December 2016; accepted 08 June 2017; published 15 August 2017

\begin{abstract}
Ionic liquids have potential for use as novel high-performance lubricants because of their attractive characteristics such as low volatility, high-thermal stability, and oxidation stability. It is known that ionic liquids exhibit excellent lubricity for metals because of halogen constituents in their molecular structure. However, occurrence of corrosive damage on the contacting surfaces lubricated with the ionic liquids has also been reported. To prevent damage due to corrosion, it is necessary to use halogen-free ionic liquids whose lubricity may be inferior compared with that of halogen-containing ionic liquids. In this study, the lubricity of halogen-free ionic liquids 1-butyl-3-methylimidazolium dicyanamide ([BMIM][DCN]) and 1-butyl-3-methylimidazolium tricyanomethane ([BMIM][TCC]) was evaluated by using a reciprocating sliding friction and wear tester (SRV Optimol)) using an oscillating steel cylinder on H-free DLC disk test configuration under boundary lubrication conditions. The SRV test results showed that H-free DLC with [BMIM][TCC] at 50N exhibited superior lubricity than that with $[\mathrm{BMIM}][\mathrm{DCN}]$ at the same load. In order to understand the observed, the worn surfaces of test specimens were analyzed by using Raman spectroscopy, the friction coefficient of the film by atomic force microscopy (AFM), and the chemical composition by time of flight secondary ion mass spectrometry (TOF-SIMS). From Raman spectroscopic analysis results, graphitization of the transfer films of both [BMIM][DCN] and [BMIM][TCC] did not occur. From AFM results, the topography of [BMIM][TCC] was smooth as compared with that of [BMIM][DCN]. Thus, it was considered that the surface roughness affected the lubricity. In addition, the tribofilm derived from [BMIM][TCC] also affected the lubricity because it showed low friction coefficient on the flat position. From ToF-SIMS results, it was considered that [BMIM][DCN] itself adsorbed on H-free DLC surface. On the other hand, [BMIM][TCC] is thermally decomposed by friction and generated isolated $\mathrm{CN}$ and covering the H-free DLC surface. The tribofilm formed by [BMIM][TCC] exhibited lower friction coefficient than that by [BMIM][DCN].
\end{abstract}

\section{Keywords}

ionic liquid, hydrogenated free diamond-like carbon, ToF-SIMS, halogen-free, AFM

\section{Introduction}

Ionic liquids, which comprise cation and anion, are organic salts in liquid state at room temperature. They have potential for use as novel high-performance base oils and/or additives because of their various attractive characteristics such as low volatility and high thermal and oxidation stability [1-9]. It has earlier been reported that ionic liquids with halogen elements in their structure exhibit excellent lubricity for metallic materials, but severe corrosion occurs on the wear track of contacting surfaces [10-15]. To prevent the occurrence of corrosive wear, the use of halogen-free ionic liquids has been proposed. The use of halogen-free ionic liquids will provide lubrication without the risk of corrosion damage but their lubricating effectiveness may be inferior compared to that of the halogen-containing ionic liquids [10-17].

In authors' previous study, the lubricity of various combinations of halogen-free ionic liquids and sliding materials such as metals, ceramics, and diamond-like carbon films was investigated. Diamond-like carbon (DLC) films are eco-friendly hard coatings with superior mechanical and tribological properties. DLC coatings are increasingly used for controlling friction and wear in many tribological applications [17-19]. In the case of "hydrogen free diamond-like carbon (H-free DLC)", improvement of lubricity was observed by using two kinds of halogen-free ionic liquids (1-butyl-3-methylimidazolium dicyanamide and 1-butyl-3-methylimidazolium tricyanomethane) [17]. However, the lubrication mechanism of this improvement has not been fully explained. The understanding of the 
lubrication mechanism is necessary in developing design concepts for the selection of optimal (compatible) combinations of ionic liquids and coating surfaces.

In this study, an attempt has been made to explain this mechanism through friction and wear properties studies on DLC coating in conjunction with steel when lubricated with ionic liquids. The lubricity of two types of ionic liquids was evaluated using steel against $\mathrm{H}$-free DLC coating by using a reciprocating sliding friction and wear tester (SRV Optimol)). In order to investigate the friction phenomena of contacting surfaces, various surface analyses techniques such as Raman spectroscopy, atomic force microscopy (AFM), and time-of-flight secondary ion mass spectrometry (TOF-SIMS) were used.

\section{Experimental work}

\subsection{Lubricants and materials}

Two types of halogen-free ionic liquids were used as lubricants: 1-butyl-3-methylimidazolium dicyanamide ([BMIM][DCN]) and 1-butyl-3-methylimidazolium tricyanomethane ([BMIM][TCC]). The molecular structures and salient properties of these ionic liquids are listed in Table 1. Both [BMIM][DCN] and [BMIM][TCC] are comprised of the same cations but structurally different forms of anions. The high-purity grade (> 98\%) ionic liquids were procured from Merck Chemicals, Germany. These ionic liquids were used without further purification. Their viscosities were measured by using a tuningfork vibration viscometer (SV-1A, A \& D Company, Japan).

For tribological tests, steel cylinders (diameter: $15 \mathrm{~mm}$; length: 22 $\mathrm{mm}$; AISI 52100 steel) and steel disks (diameter: $24 \mathrm{~mm}$; thickness: $7.9 \mathrm{~mm}$; AISI 52100 steel) with H-free DLC coating were used as tests specimens. The H-free DLC coated steel disk specimens were produced by ITF Co, (Kyoto, Japan) using an arc ion plating method. Table 2 shows the physical properties of the $\mathrm{H}$-free DLC film. The physical properties were characterised by using a tribo-indenter (Ti950, Hysitron, US), a coating thickness analyzer (Calotest, Anton Paar Tritec SA, Switzerland), and an elastic recoil detection analysis (ERDA) technique.

\subsection{Tribological tests}

Figure 1 shows the schematic of an oscillating sliding friction and wear tester (SRV4, Optimol, Germany) for evaluating the lubricity of the ionic liquids. The test specimens were ultrasonically cleaned before and after the tests with a solution of petroleum benzine and acetone for $10 \mathrm{~min}$. A volume of $120 \mu \mathrm{L}$ of the ionic liquid was applied onto the surface of the DLC coated disk and its temperature was raised to a specified value before starting the test. The operating parameters for tribological tests were: temperature $=50^{\circ} \mathrm{C}$, load $=50,100$, and $200 \mathrm{~N}$, reciprocating frequency $=50 \mathrm{~Hz}$, amplitude $=1 \mathrm{~mm}$, and test duration $=60 \mathrm{~min}$. All tribological tests were carried out at least five times. The repeat test results showed good reproducibility.

2.3 Raman spectroscopy analysis

The structural changes in the DLC films on the inside and

Table 2 Physical property of H-free DLC

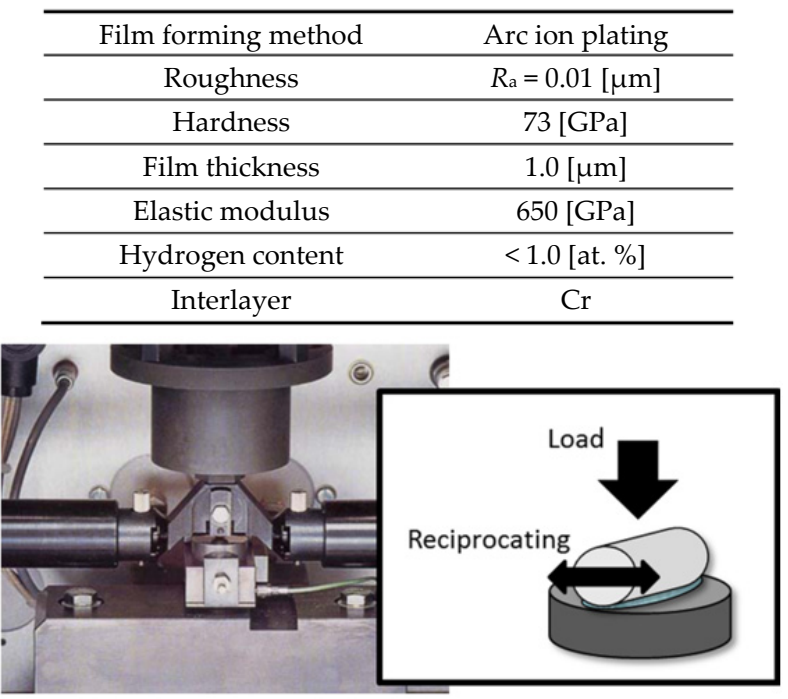

Fig. 1 Schematic of oscillating sliding friction and wear tester

Table 1 Salient properties of ionic liquids

\begin{tabular}{|c|c|}
\hline & $\begin{array}{l}\text { 1-Butyl-3-methylimidazolium dicyanamide } \\
{[\text { [BMIM] }[\mathrm{DCN}]}\end{array}$ \\
\hline Viscosity $\left(50^{\circ} \mathrm{C}\right)$ & $11.6[\mathrm{mPa} \cdot \mathrm{s}]$ \\
\hline Melting Point & $<-50\left[{ }^{\circ} \mathrm{C}\right]$ \\
\hline Purity & $>98[\%]$ \\
\hline Density & $229.28[\mathrm{~g} / \mathrm{mol}]$ \\
\hline Thermal stability & $300\left[{ }^{\circ} \mathrm{C}\right]$ \\
\hline \multirow[t]{2}{*}{$\begin{array}{l}\text { Structural } \\
\text { Diagram }\end{array}$} & \\
\hline & $\begin{array}{l}\text { 1-Butyl-3-methylimidazolium tricyanomethane } \\
\text { [BMIM][TCC] }\end{array}$ \\
\hline Viscosity $\left(50^{\circ} \mathrm{C}\right)$ & $11.1[\mathrm{mPa} \cdot \mathrm{s}]$ \\
\hline Melting Point & $<-50\left[{ }^{\circ} \mathrm{C}\right]$ \\
\hline Purity & $>98[\%]$ \\
\hline Density & $205.26[\mathrm{~g} / \mathrm{mol}]$ \\
\hline Thermal stabiligy & $344\left[{ }^{\circ} \mathrm{C}\right]$ \\
\hline $\begin{array}{c}\text { Structural } \\
\text { Diagram }\end{array}$ & N \\
\hline
\end{tabular}


outside of the disk wear track were investigated by Raman spectroscopy (NRS-3200, JASCO, Japan). The Raman spectra were obtained by using a 514-nm diode laser with a maximum output power of $0.5 \mathrm{~mW}$ in conjunction with an objective lens at 20x magnification. The visible Raman spectra of the amorphous carbon showed some prominent features (D-peak at approximately $1300-1400 \mathrm{~cm}^{-1}$ and G-peak at $1500-1600 \mathrm{~cm}^{-1}$ ) [21]. In this study, the degree of graphitization was estimated by using G-peak intensities. It is known that the graphitization (increasing of G-peak intensities) of the film has an effect on friction behavior [22]. In view of this, the effect of structural change of DLC film on the tribological behavior was investigated.

\subsection{AFM analysis}

The surface features of the wear track of the disk were analyzed by AFM (Nanoscope IIIA, Veeco, US; and Nanonavi Real, SII, Japan) using frictional force microscopy (FFM). AFM was used for obtaining the topographic and friction images. The sample surface was scanned with a stylus attached to a cantilever. The friction coefficients in the frictional curve mode were measured. The vertical motion of the cantilever was recorded in AFM and horizontal motion was recorded in FFM, respectively. The tip of the cantilever was silicon (SI-DF03). The conditions for AFM were: vertical amplitude $=100 \mathrm{~nm}$, scanning area $=1 \mu \mathrm{m} \times 1$ $\mu \mathrm{m}$, load $=87-396 \mathrm{nN}$. Conversion mathematical formula shows below:

$$
\mu=0.4 \times C t \times \frac{W}{L} \times V /(S \times N)
$$

Where $\mu$ is the friction coefficient, $C t$ is the torsional spring constant, $W$ is the length of probe, $L$ is the length of cantilever, $V$ is the output value, $S$ is the DIF sensitivity, and $N$ is the load.

\subsection{ToF-SIMS analysis}

The chemical composition of the wear track of the disk was analyzed by using ToF-SIMS (ULVAC TRIFT III, URVAC PHI, Japan) in order to confirm the adsorption and reaction of the ionic liquids on the wear track. A pulsed electron impact ion source $\left(15 \mathrm{keV}, 69 \mathrm{Ga}^{+}\right)$was used to generate primary ions for the analysis. The analysis area on the sample surface was $100 \mu \mathrm{m} \times$ $100 \mu \mathrm{m}$. Ion irradiation time was $5 \mathrm{~min}$. Measured mass range was $0.5-2000 \mathrm{~m} / \mathrm{e}$. Mass resolution was 500 at $\mathrm{m} / \mathrm{z}=27(\mathrm{Al})$. Lateral resolution was $2 \mu \mathrm{m}$. The sample surface was ultrasonically cleaned with a solution of petroleum benzine and acetone for $10 \mathrm{~min}$.

\section{Results}

\subsection{Friction}

Figures $(2,3)$ show the variation of friction coefficients of [BMIM][DCN] and [BMIM][TCC] as function of time respectively. When [BMIM][DCN] was used, the friction coefficient under all test loads showed stable behavior and attained a value of approximately 0.13 soon after the commencement of the test. On the other hand, in the case of [BMIM][TCC] at $50 \mathrm{~N}$, the friction coefficient rapidly decreased in the beginning of the test and reached a value of approximately 0.02 after $500 \mathrm{~s}$. However, at 100 and $200 \mathrm{~N}$, the friction coefficient fluctuated in the beginning of the test and then stabilized at approximately 0.10 after $1000 \mathrm{~s}$. At 100 and $200 \mathrm{~N}$, the H-free DLC film was detached from the steel substrate after the friction test.

The wear scar widths of the cylinders for $[\mathrm{BMIM}][\mathrm{DCN}]$ and [BMIM][TCC] are shown in Fig. 4. The wear scar widths for [BMIM][DCN] and [BMIM][TCC] increased with increasing load. In the case of [BMIM][DCN], the effect of load on wear scar width

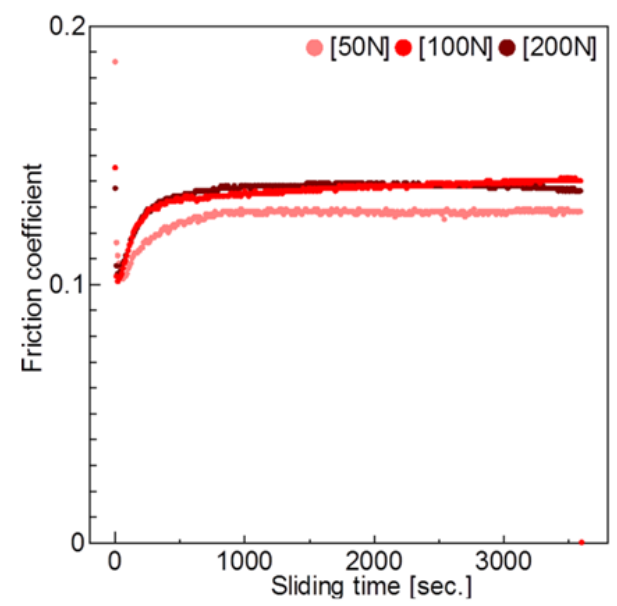

Fig. 2 Time variation of friction coefficient of [BMIM] [DCN]

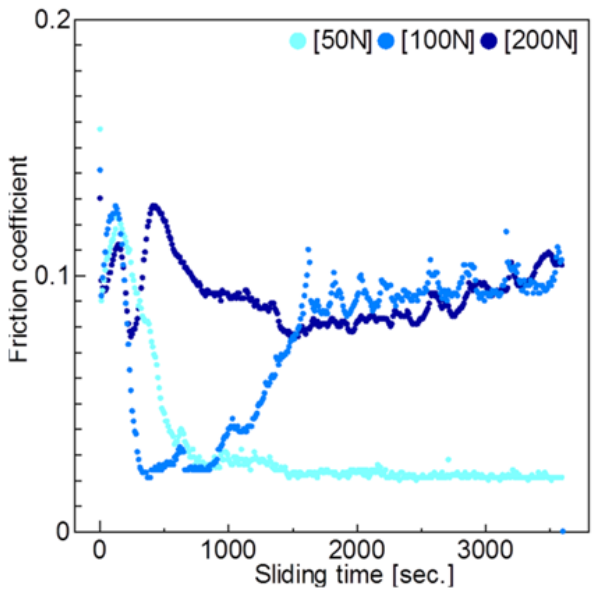

Fig. 3 Time variation of friction coefficient of [BMIM] [TCC]

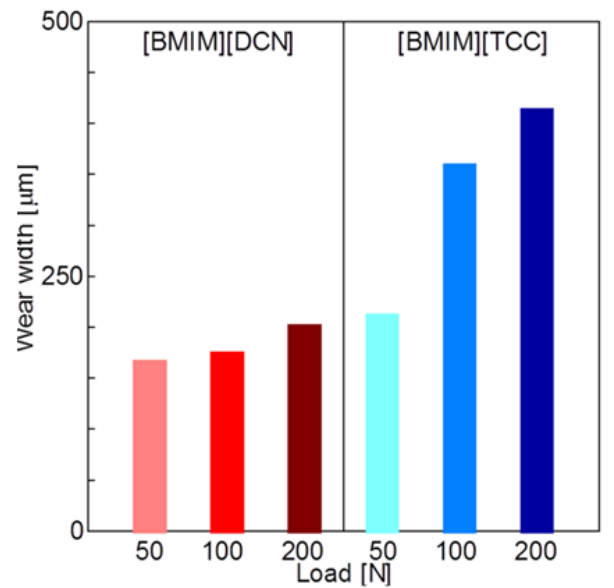

Fig. 4 Wear scar width of cylinder at different loads

was marginal but for [BMIM][TCC], the wear scar width at $50 \mathrm{~N}$ was significantly smaller than that under the other load conditions. It was considered that the detachment of H-free DLC from the steel substrate led to the large wear scar width at higher loads in case of [BMIM][TCC],. In other words, the similar material contacts showed poor lubricity. Kondo et al [12] have earlier reported poor lubricity of ionic liquids in the steel/steel contact configuration.

These results indicate that the tribological properties of the 
ionic liquids can be modified by using anions of different molecular structures. The anion dependence of the tribological properties can be explained by three possibilities. One is the structural change in the $\mathrm{H}$-free DLC film surface that can be induced by the existence of different anions on the wear track. Another is the differences in the properties of the formed tribofilms due to tribochemical reactions of the anions with the DLC coating surface. The other is the surface roughness. To investigate he friction reduction effect of the anion, the various surface analyses was carried out at $50 \mathrm{~N}$.

\subsection{Raman spectroscopy analysis results}

Raman spectroscopic analysis was performed to investigate the structural changes in the H-free DLC. Figures $(5,6)$ show Raman spectra of [BMIM][DCN] and [BMIM][TCC], respectively. The inside and outside of the wear track of the H-free DLC coating from tests at $50 \mathrm{~N}$ load for each ionic liquid were analyzed. In this study, the degree of graphitization was estimated by $G$ intensities [23-27]. We defined the G-peak at approximately $1550 \quad \mathrm{~cm}^{-1}$. No significant structural transformation in the spectral shape was observed for the inside or outside of the H-free DLC wear track for the any of the ionic liquids investigated. Thus, it was able to interpret that the graphitization was not occurred. The friction results indicate that graphitization did not affect the friction reduction.

\subsection{AFM results}

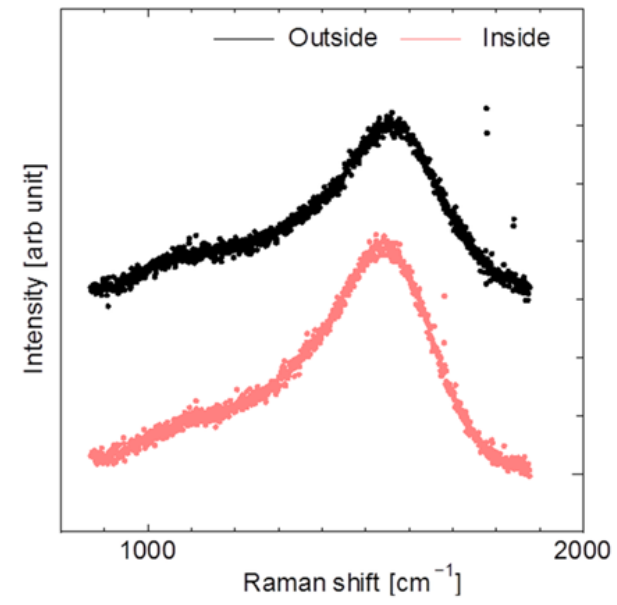

Fig. 5 Raman spectra of [BMIM][DCN] at inside and outside of wear track in the range of $800-2000 \mathrm{~cm}^{-1}$

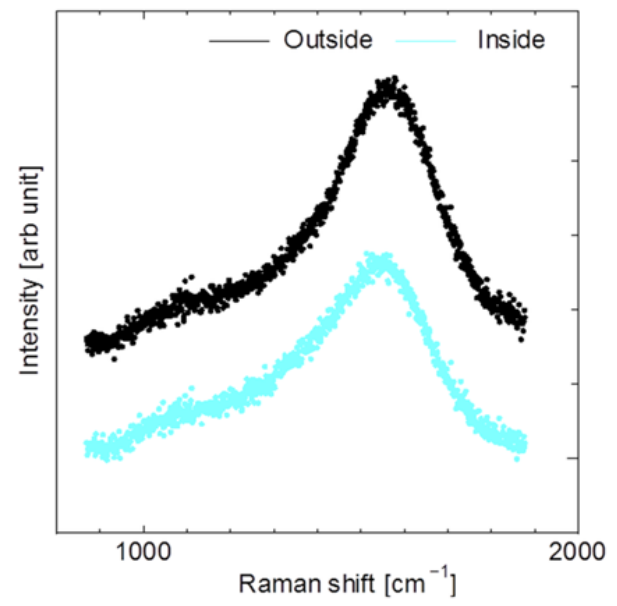

Fig. 6 Raman spectra of [BMIM][TCC] at inside and outside of wear track in the range of $800-2000 \mathrm{~cm}^{-1}$
AFM analysis was performed to investigate the differences in the properties of the formed tribofilms. Topographic and friction force images from tests using [BMIM][DCN] and [BMIM][TCC] with a load of $50 \mathrm{~N}$ on the disk are shown in Figs. $(7,8)$, respectively. The topographic images show large difference in height for [BMIM][DCN] [Fig. 7(a)] compared with [BMIM][TCC] [Fig. 7(b)]. On the other hand, the friction force of [BMIM][TCC] [Fig. 8(a)] was smaller than that of [BMIM] [DCN] [Fig. 8(b)]. It is considered that the surface roughness affected the frictional force because the topography of [BMIM][TCC] was smooth as compared with that of [BMIM][DCN]. Therefore, we measured friction by using AFM in the region where the topographic effect did not perturb the friction force. In other words, we chose the flat position and measured friction force on there. The frictional curve of each ionic liquid is shown in Fig. 9. The friction
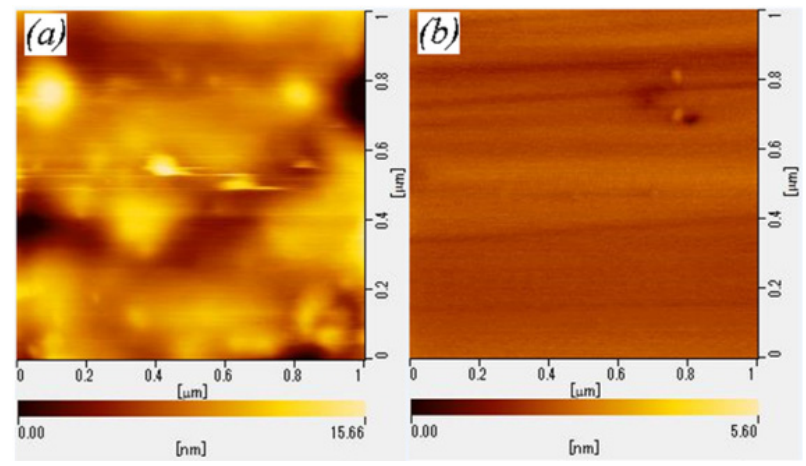

Fig. 7 AFM results - Topographic image of (a) $[\mathrm{BMIM}][\mathrm{DCN}],(\mathrm{b})[\mathrm{BMIM}][\mathrm{TCC}]$

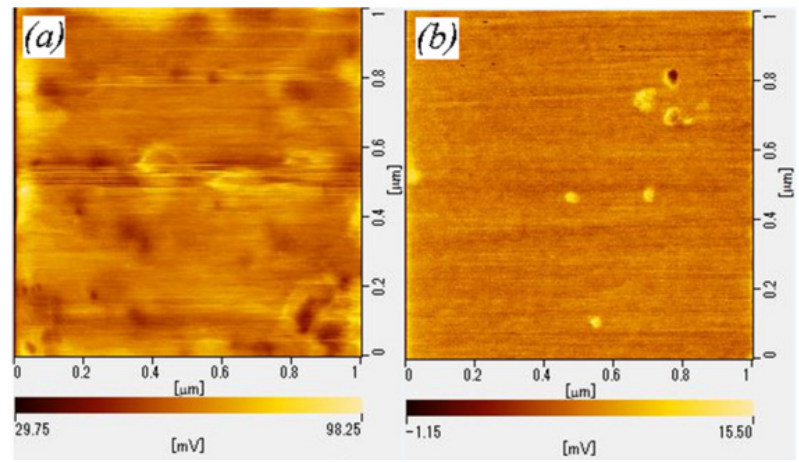

Fig. 8 AFM result - Friction force image of (a) $[\mathrm{BMIM}][\mathrm{DCN}]$ (b) $[\mathrm{BMIM}][\mathrm{TCC}]$

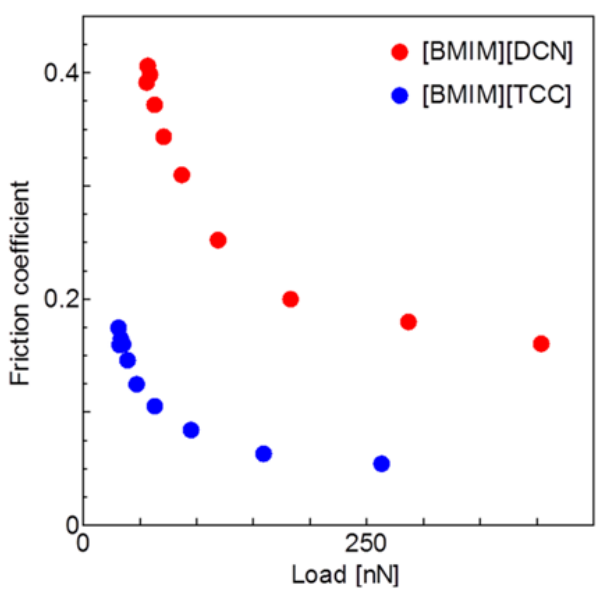

Fig. 9 AFM result - Friction coefficient of [BMIM][DCN] and [BMIM][TCC] 
coefficients in case of [BMIM][TCC] were lower than that of [BMIM][DCN] at all loads. From the results of the AFM analysis, it was considered that not only surface roughness but also properties of the tribofilm affected tribological properties.

3.4 ToF-SIMS results

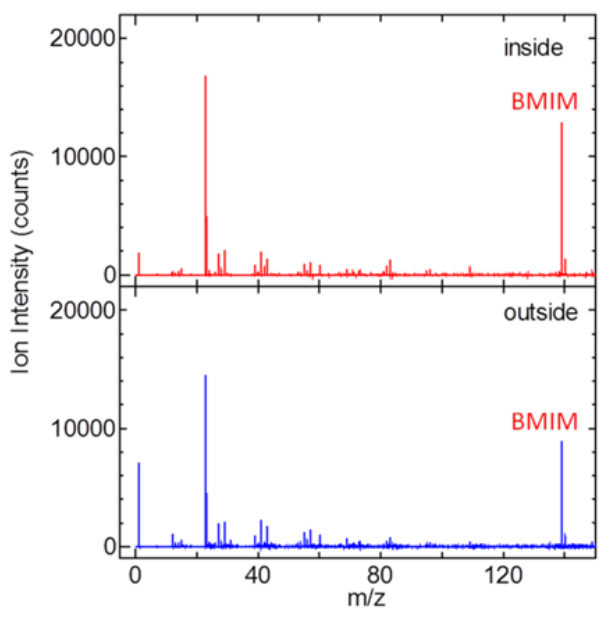

Fig. 10 TOF-SIMS spectrum of [BMIM][DCN] in positive ion mode

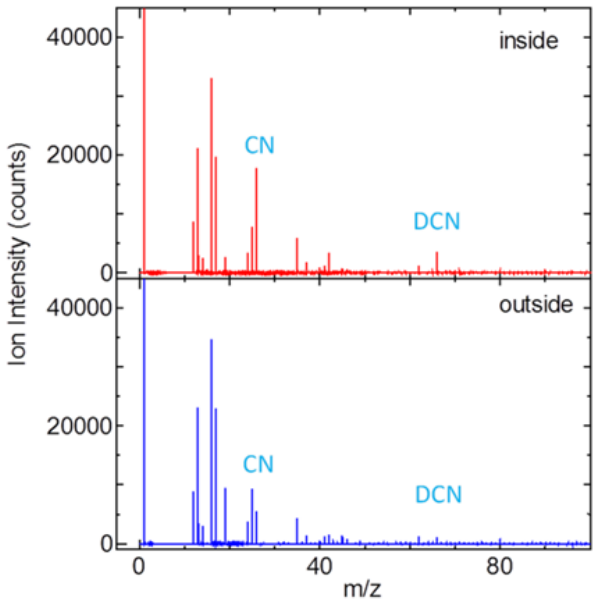

Fig. 11 TOF-SIMS spectrum of [BMIM][DCN] in negative ion mode

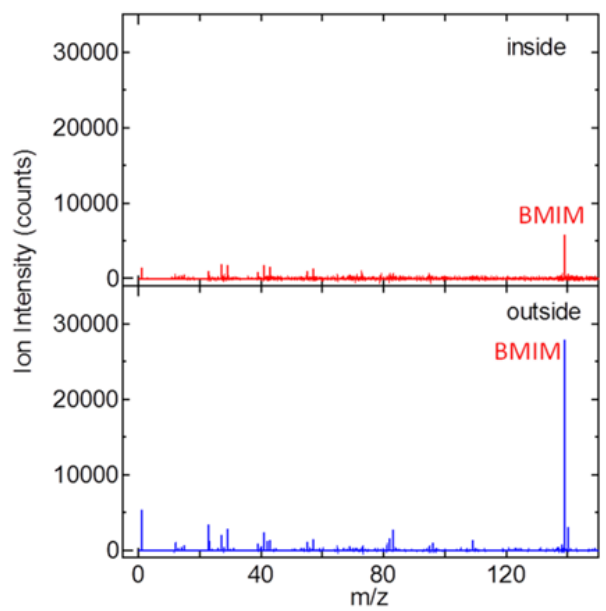

Fig. 12 TOF-SIMS spectrum of [BMIM][TCC] in positive ion mode
Figures (10-13) show the spectra of the TOF-SIMS analysis of the disk surface for each ionic liquid from tests at a load of $50 \mathrm{~N}$ and Figures $(14,15)$ show the ion count ratios. The ion count ratio was estimated by calculating the ratio of optional mass count to all mass count. The cation and anion of both ionic liquids

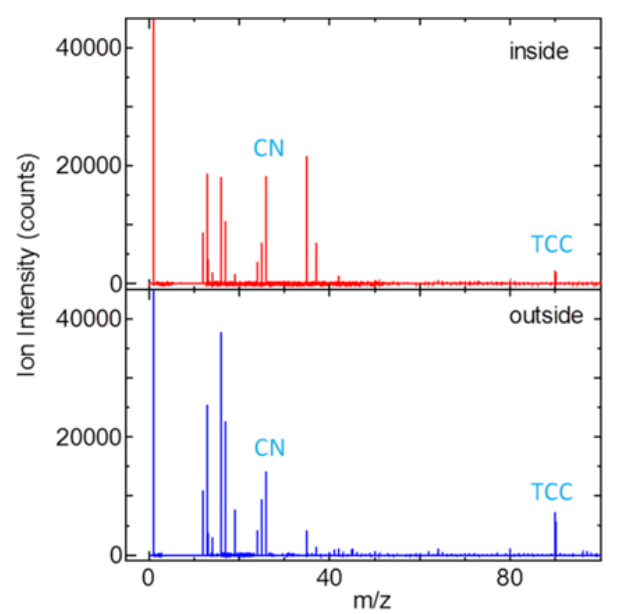

Fig. 13 TOF-SIMS spectrum of [BMIM][TCC] in negative ion mode

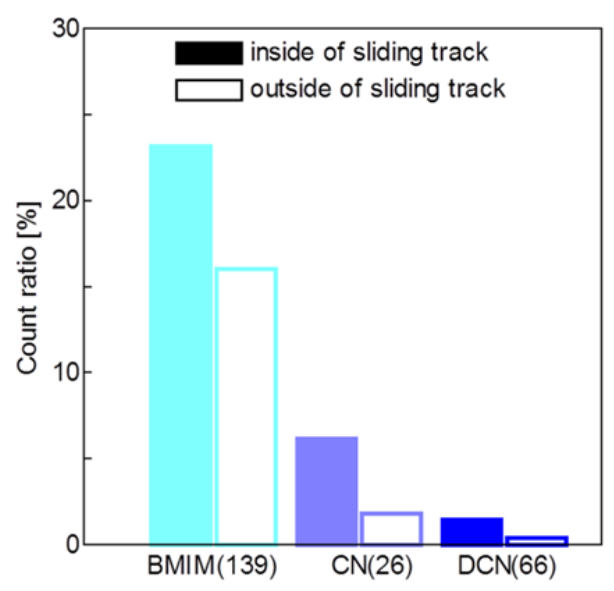

Fig. 14 Ion count ratio of [BMIM][DCN]

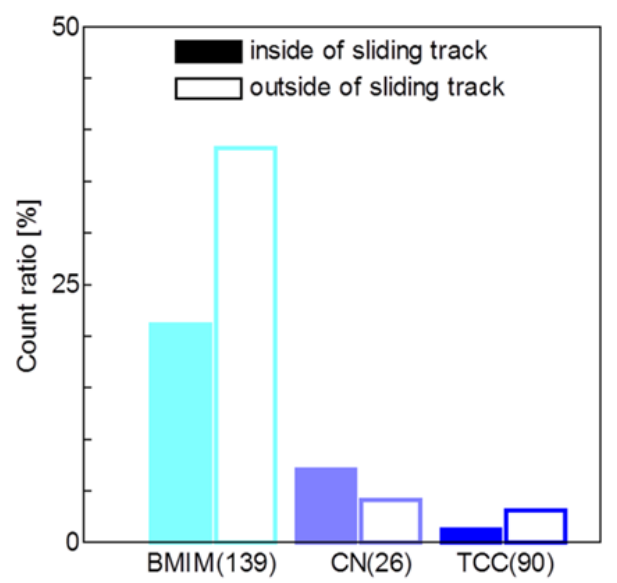

Fig. 15 Ion count ratio of [BMIM][TCC] 


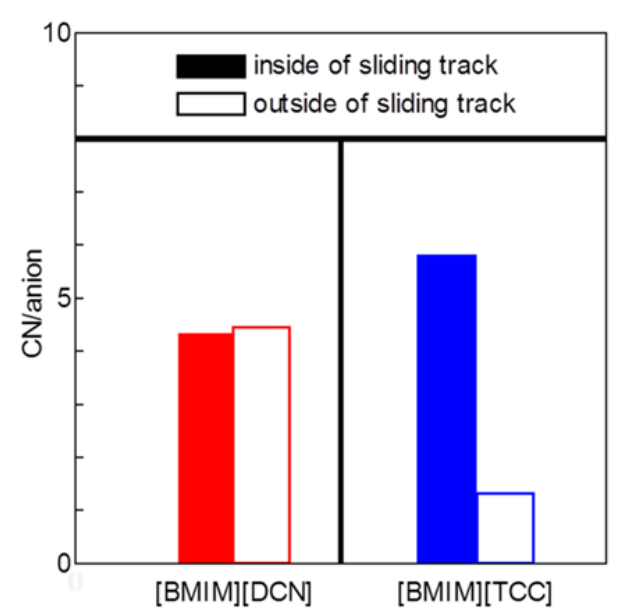

Fig. 16 Values of $\mathrm{CN} /$ anion from ion count ratio

adsorbed on disk surface. About 35 and $37 \mathrm{~m} / \mathrm{z}$, it was considered that the effect of impurity (chlorine). This element is not include in the ionic liquids. We removed the effect of chlorine on the lubricity. In the case of [BMIM][DCN], the intensities of cation and anion on the sliding track were large compared to those on the outside of sliding track. On the other hand, the intensities of cation and anion on the sliding track with [BMIM][TCC] were small compared to those on the outside of sliding track. However, $\mathrm{CN}$ on the inside of sliding track showed large ion intensities. This molecule is end group of TCC anion. This result indicates that anion of [BMIM][TCC] was decomposed by the sliding action and $\mathrm{CN}$ adsorbed on the sliding track of the H-free DLC.

The anion decomposition may be a possible reason for this difference in adsorption species. By using the results in Figs. 14 and 15 , the $\mathrm{CN}$ ratio, which is defined as the ratio of the content of $\mathrm{CN}$ at $\mathrm{m} / \mathrm{z} 26$ to that of the anions (sum of $\mathrm{C}_{2} \mathrm{~N}_{3}$ and $\mathrm{C}_{4} \mathrm{~N}_{3}$ ) was calculated. Figure 16 shows the $\mathrm{CN}$ ratio of each ionic liquid. The $\mathrm{CN}$ ratio of [BMIM][DCN] inside the wear track was similar to that outside the wear track. This result indicates that $[\mathrm{BMIM}][\mathrm{DCN}]$ itself was adsorbed on the sliding track of the H-free DLC. However, the CN ratio of [BMIM][TCC] inside the wear track was four times higher than that outside the wear track.

\section{Discussion}

The AFM results [BMIM][TCC] exhibited smooth surface and low friction as compared with [BMIM][DCN]. It was considered that the surface roughness affected the tribological properties. In addition, the tribofilm derived from ionic liquids also affected the tribological properties because [BMIM][TCC] showed low friction coefficient on the flat position. About the tribofilm derived from ionic liquids, the ToF-SIMS results in the case of [BMIM][DCN] show that the anions themselves are adsorbed on the wear track of the $\mathrm{H}$-free DLC because the CN ratio of [BMIM][DCN] inside the wear track was similar to that outside the wear track. This suggests that the [BMIM][DCN] is thermally decomposed by friction, however, [DCN] anion combine with alkyl-chain of [BMIM] [28]. After that, [BMIM][DCN] adsorbed on nascent DLC surface. A schematic of the molecular adsorption model of [BMIM] $[D C N]$ is shown in Fig. 17. On the other hand, in the case of [BMIM][TCC], the $\mathrm{CN}$ ratio of [BMIM][TCC] inside the wear track was four times higher than that outside the wear track. This suggests that the [BMIM][TCC] is thermally decomposed by friction and generated isolated $\mathrm{CN}$ and covering the $\mathrm{H}$-free DLC surface. A schematic of the molecular adsorption model of

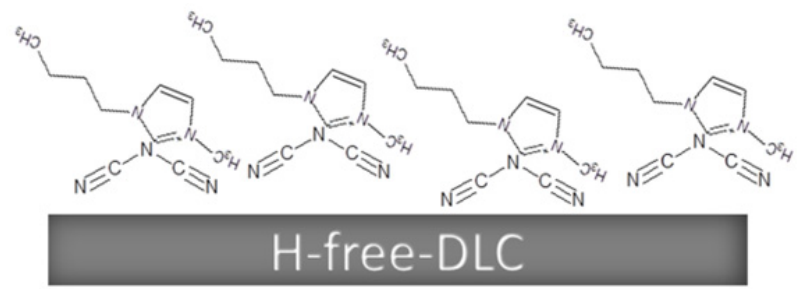

Fig. 17 Molecular adsorption model of [BMIM][DCN]

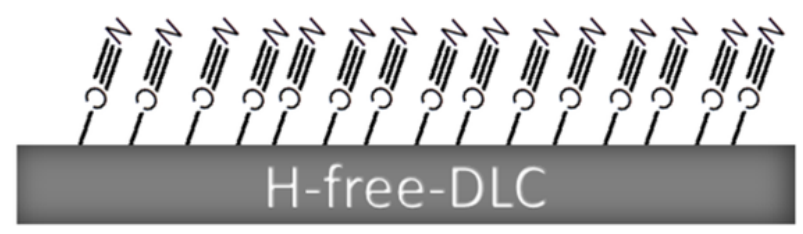

Fig. 18 Molecular adsorption model of [BMIM][TCC]

[BMIM][TCC] is shown in Fig. 18. From the results of friction tests, [BMIM][TCC] showed lower friction coefficient than that of $[\mathrm{BMIM}][\mathrm{DCN}]$.

\section{Conclusion}

The tribological properties of two different ionic liquids for $\mathrm{H}$-free DLC were investigated by using various surface analyses techniques, including Raman spectroscopy, AFM, and TOF-SIMS. The main conclusions are as follows:

(1) The lubricity of halogen-free ionic liquids against $\mathrm{H}$-free DLC is determined by the structure of the anion.

(2) The Raman spectroscopic analysis revealed that graphitization of the transfer films of both [BMIM][DCN] and [BMIM][TCC] did not occur after a friction test at $50 \mathrm{~N}$.

(3) From the AFM results, topography of [BMIM][TCC] was smooth as compared with that of [BMIM] [DCN].

(4) Both [BMIM][DCN] and [BMIM][TCC] formed tribofilms induced by sliding as seen from ToF-SIMS measurements. In addition, as compared to $[\mathrm{BMIM}][\mathrm{DCN}]$, the tribofilm derived from [BMIM][TCC] had a higher friction reducing effect by the results of AFM. The CN ratio of [BMIM][DCN] inside the wear track was similar to that outside. However, the $\mathrm{CN}$ ratio of [BMIM][TCC] inside the wear track was four times higher than that outside the wear track. It was considered that [BMIM][DCN] itself adsorbed on H-free DLC surface. On the other hand, [BMIM][TCC] is thermally decomposed by friction and generated isolated $\mathrm{CN}$ and covering the $\mathrm{H}$-free DLC surface.

These mechanism was obtained by the results of only ToF-SIMS. For further understanding of mechanism, we plan to use another analytical method such as in-situ FT-IR, in-situ Raman, and in-situ SFG.

In addition, it remain unknown which of these possibility, surface roughness and tribofilm derived from ionic liquids, had greater impact. It is required the detail analysis.

\section{Acknowledgments}

This work was supported by a Grant-in-Aid for Japan Society for the Promotion of Science (JSPS) Fellows (No. 15J05958). 


\section{References}

[1] Ye, C., Liu, W., Chen, Y. and Yu, L., "Room-Temperature Ionic Liquids: a Novel Versatile Lubricant," Chemical Communications, 2001, 2244-2245.

[2] Kamimura, H., Kubo, T., Minami, I. and Mori, S., "Effect and Mechanism of Additives for Ionic Liquids as New Lubricants," Tribology International, 40, 4, 2007, 620-625.

[3] Bermudez, M. D., Jimenez, A. E., Sanes, J. and Carrion, F. J., “Ionic Liquids as Advanced Lubricant Fluids," Molecules, 14, 8, 2009 , 2888-2908.

[4] Zhou, F., Liang, Y. and Liu, W., "Ionic Liquid Lubricants: Designed Chemistry for Engineering Applications," Chemical Society Reviews, 38, 2009, 2590-2599.

[5] Doerr, N., Gebeshuber, I. C., Holzer, D., Wanzenboeck, H. D., Ecker, A., Pauschitz, A. and Franek, F., "Evaluation of Ionic Liquids as Lubricants," Journal of Microengineering and Nanoelectronics, 1, 1, 2010, 29-34

[6] Schlucker, E. and Waserscheid, P., "Ionic Liquids in Mechanical Engineering," Chemie Ingenieur Technik, 83, 2011, 1476-1484.

[7] Canter, N., "Using Dicationic Liquids Liquids as High Temperature Lubricants," Tribology \& Lubrication Technology, 63, 5, 2007, 12-13.

[8] Philips, B. S. John, G. and Zabinski, J. S., "Surface Chemistry of Fluorine Containing Ionic Liquids on Steel Substrates at Elevated Temperature Using Mössbauer Spectroscopy," Tribology Letters, 26, 2, 2007, 85-91.

[9] Suzuki, A., Shinka, Y. and Masuko, M., "Tribological Characteristics of Imidazolium-Based Room Temperature Ionic Liquids under High Vacuum," Tribology Letters, 27, 3, 2007, 307-313.

[10] Minami, I., “Ionic Liquids in Tribology,” Molecules, 14 2009, 2286-2305.

[11] Minami, I., Inada, T. and Okada, Y., "Tribological Properties of Halogen-Free Ionic Liquids," Inst., Mech., Eng., Part J, Journal of Engineering Tribology, 226, 11, 2011, 891-902.

[12] Kondo, Y., Yagi, S., Koyama, T., Tsuboi, R. and Sasaki, S., "Lubricity and Corrosiveness of Ionic Liquids for Steel-on-Steel Sliding Contacts," Inst., Mech., Eng., Part J, Journal of Engineering Tribology, 226, 11, 2011, 991-1006.

[13] Kinoshita, H., Kondo, M., Nishina, Y. and Fujii, M., "Anti-Wear Effect of Graphene Oxide in Lubrication by Fluorine-Containing Ionic Liquid for Steel," Tribology Online, 10, 1, 2015, 91-95.

[14] Kamimura, H., Chiba, T., Watanabe, N., Kubo, T., Nanao, H., Minami, I. and Mori, S., "Effects of Carboxylic Acids on Friction and Wear Reducing Properties for Alkylmethylimidazolium Derived Ionic Liquids," Tribology Online, 1, 2, 2006, 40-43
[15] Kobayashi, K., Suzuki, A., Fujinami, Y., Nogi, T., Obara, S. and Masuko, M., "Lubrication Performance of Ionic Liquids as Lubricants for Space Mechanisms under High Vacuum and Low Temperature," Tribology Online, 10, 2, 2015, 138-146.

[16] Kawada, S., Watanabe, S., Kondo, Y., Tsuboi, R. and Sasaki S., "Tribochemical Reactions of Ionic Liquids under Vacuum Conditions," Tribology Letters, 54, 3, 2014, 309-315.

[17] Kondo, Y., Koyama, T., Tsuboi, R., Nakano, M., Miyake, K. and Sasaki, S., "Tribological Performance of Halogen-Free Ionic Liquids as Lubricants of Hard Coatings and Ceramics," Tribology Letters, 51, 2, 2013, 243-249.

[18] Robertson, J., “Diamond-Like Amorphous Carbon,” Materials Science and Engineering R, 37,4-6, 2002, 129-281.

[19] Bewilogua, K., Brauer, G., Dietz, A., Gabler, J., Goch, G., Karpuschewshi, B. and Szyszka, B., "Surface Technology for Automotive Engineering," CIRP Annals, Manufacturing Technology, 58, 2009, 608-627.

[20] Wang, L. and Liu, X., “Tribological behavior of DLC/IL Solid-Liquid Lubricating Coatings in a High-Vacuum Condition with Alternating High and Low Temperatures," Wear, 304, 1-4, 2013, 13-19.

[21] Ferrari, A. C. and Robertson, J., "Interpretation of Raman Spectra of Disordered and Amorphous Carbon," Physical Review B, 61, 2000, 14095-14107.

[22] Liu, Y., Erdemir, A., Meletis, E. I., "An Investigation of the Relationship Graphitization and Frictional behavior of DLC Coatings," Surface and Coatings Technology, 86-87, 2, 1996, 564-568.

[23] Sanchez-Lopez, J. C., Erdemir, A., Donnet, C. and Rojas, T. C., "Friction-Induced Structural Transformations of Diamondlike Carbon Coatings under Various Atmospheres," Surface and Coatings Technology, 163-164, 2003, 444-450.

[24] Miura, K. and Nakamura, M., "Analysis of Hydrogen Concentration in DLC Films by Raman Spectroscopy," Journal of the Surface Finishing Society of Japan, 59, 3, 2008, 203-205 (in Japanese).

[25] Vengudusamy, B., Mufti, R. A., Lamb, G. D., Green, J. H. and Spikes, H. A., "Friction Properties of DLC/DLC Contacts in Base Oil," Tribology International, 44, 7-8, 2011, 922-932.

[26] Kawaguchi, M., Aoki, S., Mitsuo, A., Morikawa, K., Uchida, S., Choi, J. and Kato, T., "Estimation of DLC Wear Process by Micro Lased Raman Spectroscopy," Tribology Online, 3, 2, 2008, 110-115.

[27] Tokuta, Y., Kawaguchi, M., Shimizu, A. and Sasaki, S., "Effects of Applied Heat and Stress on Structural Changes of DLC Film," Tribology Online, 7, 3, 2012, 119-126.

[28] Cedric, M., Nils, D. V. and Christian, V. S., "Ionic Liquid Thermal Stabilities: Decomposition Mechanisms and Analysis Tools," Chem. Soc. Rev., 42, 2013, 5963-5977. 